\title{
Shockwave Dosing Unit
}

National Cancer Institute

\section{Source}

National Cancer Institute. Shockwave Dosing Unit. NCI Thesaurus. Code C112433.

A dosing measurement based on the shock wave unit. 